\title{
New and improved infrared absorption cross sections for chlorodifluoromethane (HCFC-22)
}

\author{
Jeremy J. Harrison ${ }^{1,2}$ \\ ${ }^{1}$ Department of Physics and Astronomy, University of Leicester, University Road, Leicester, LE1 7RH, UK \\ ${ }^{2}$ National Centre for Earth Observation, University of Leicester, University Road, Leicester, LE1 7RH, UK \\ Correspondence to: Jeremy J. Harrison (jh592@leicester.ac.uk)
}

Received: 10 December 2015 - Published in Atmos. Meas. Tech. Discuss.: 18 January 2016

Revised: 3 May 2016 - Accepted: 6 May 2016 - Published: 17 June 2016

\begin{abstract}
The most widely used hydrochlorofluorocarbon (HCFC) commercially since the 1930s has been chlorodifluoromethane, or HCFC-22, which has the undesirable effect of depleting stratospheric ozone. As this molecule is currently being phased out under the Montreal Protocol, monitoring its concentration profiles using infrared sounders crucially requires accurate laboratory spectroscopic data. This work describes new high-resolution infrared absorption cross sections of chlorodifluoromethane over the spectral range $730-1380 \mathrm{~cm}^{-1}$, determined from spectra recorded using a high-resolution Fourier transform spectrometer (Bruker IFS 125HR) and a $26 \mathrm{~cm}$ pathlength cell. Spectra of chlorodifluoromethane/dry synthetic air mixtures were recorded at resolutions between 0.01 and $0.03 \mathrm{~cm}^{-1}$ (calculated as 0.9/MOPD; MOPD denotes the maximum optical path difference) over a range of temperatures and pressures (7.5-762 Torr and 191-295 K) appropriate for atmospheric conditions. This new cross-section dataset improves upon the one currently available in the HITRAN (HIgh-resolution TRANsmission) and GEISA (Gestion et Etude des Informations Spectroscopiques Atmosphériques) databases; in particular it provides coverage over a wider range of pressures and temperatures, has more accurate wavenumber scales, more consistent integrated band intensities, improved signalto-noise, is free of channel fringing, and additionally covers the $\nu_{2}$ and $\nu_{7}$ bands.
\end{abstract}

\section{Introduction}

The consumer appetite for safe household refrigeration led to the commercialisation in the 1930s of dichlorodifluoromethane, or CFC-12, a non-flammable and non-toxic refrigerant (Myers, 2007). Within the next few decades, other chemically related refrigerants were additionally commercialised, including chlorodifluoromethane, or a hydrochlorofluorocarbon known as HCFC-22, which found use in a wide array of applications such as air conditioners, chillers, and refrigeration for food retail and industrial processes. Additionally, HCFC-22 was a component of refrigerant R-502, an azeotropic blend of $48.8 \%$ HCFC- 22 and $51.2 \%$ CFC115 by mass, introduced in the 1960s for commercial refrigeration equipment (Watanabe, 2003). The use of chlorodifluoromethane has also grown as a feedstock, for example its pyrolysis yields tetrafluoroethylene (TFE), the monomer for polytetrafluoroethylene (PTFE), which is trademarked as Teflon (Myers, 2007). Furthermore, its manufacture results in the by-product trifluoromethane, or fluoroform (HFC-23), a very strong greenhouse gas which continues to increase in the atmosphere (Harrison et al., 2012).

The discovery that CFCs (chlorofluorocarbons) could reach the stratosphere and photodissociate to release chlorine atoms, which would catalyse the destruction of stratospheric ozone (Solomon, 1999), led to international action and the ratification of the 1987 Montreal Protocol (and its later amendments), which aimed to phase out the worldwide production and use of CFCs and other ozone-depleting substances. HCFCs (hydrochlorofluorocarbons), which were not regulated until the 1992 amendment and have a less deleterious effect on the ozone layer than CFCs, were designated "transitional" replacements to aid in the rapid phase-out of 
CFCs. With the worldwide CFC phase-out achieved, the focus has shifted to ending the use of HCFCs themselves, with a final phase-out currently scheduled for 2040 in the developing world and 2030 for developed countries.

HCFCs, in particular HCFC-22, continue to increase in the atmosphere. HCFC-22 is currently the most abundant HCFC in the Earth's atmosphere; it has an ozone depletion potential of 0.034 (Harris et al., 2014), and an atmospheric lifetime of 11.9 years (Harris et al., 2014). It is also a very strong greenhouse gas with a 100-year global warming potential of 1780 (Harris et al., 2014). It is unsurprising, therefore, that there is much work carried out in monitoring HCFC-22 atmospheric concentrations. For example, according to in situ, groundbased AGAGE (Advanced Global Atmospheric Gases Experiment) measurements, the tropospheric abundance of HCFC22 increased from $191.8 \mathrm{ppt}$ in 2008 to $214.2 \mathrm{ppt}$ in 2011 to 219.8 ppt in 2012 (Carpenter et al., 2014), with a 2011-2012 growth rate of $2.6 \% \mathrm{yr}^{-1}$. However, emissions of HCFC-22 have stabilised since 2008 at $\sim 370 \mathrm{Gg} \mathrm{yr}^{-1}$ (Carpenter et al., 2014). Saikawa et al. (2012) have estimated regional HCFC22 emissions from globally distributed surface data, which indicate an increasing trend between 1995 and 2009, and a surge in HCFC-22 emissions between 2005 and 2009 from developing countries in Asia, including China and India, partially offsetting first efforts in developed countries to phaseout production and consumption. Although there is believed to be a large worldwide bank of HCFC-22 in refrigeration systems, it is expected that emissions will decline over the coming decade as new refrigerants are adopted (Carpenter et al., 2014).

Measurements of HCFC-22 in the atmosphere are also made using remote-sensing techniques. The literature reports a number of remote-sensing instruments capable of measuring HCFC-22 in the Earth's atmosphere: the ATMOS (Atmospheric Trace MOlecule Spectroscopy) instrument deployed on the space shuttle (Irion et al., 2002); the JPL balloon-borne MkIV interferometer (Velazco et al., 2011); the MIPAS (Michelson Interferometer for Passive Atmospheric Sounding) instrument on ENVISAT (ENVIronmental SATellite) (e.g. Moore and Remedios, 2008); and the ACE-FTS (Atmospheric Chemistry Experiment - Fourier transform spectrometer) instrument on SCISAT (Brown et al., 2011).

Crucially these remote-sensing datasets all rely on the accuracy of the underlying laboratory spectroscopy used in the forward model. Since the chlorodifluoromethane infrared (IR) spectrum consists of an abundance of densely packed lines, it is virtually an impossible task to derive spectroscopic line parameters. The solution for remote-sensing purposes is to derive absorption cross sections from air-broadened spectra recorded in the laboratory. In order to be most useful for remote sensing, these cross-section datasets require (1) accurate band intensities; (2) accurate wavenumber scales; (3) a wide coverage of atmospherically relevant pressuretemperature (PT) combinations; (4) spectra recorded at an appropriate resolution (Doppler-limited at the lowest pressures). This work presents new spectroscopic data which improve upon those currently available in the HITRAN (HIghresolution TRANsmission) and GEISA (Gestion et Etude des Informations Spectroscopiques Atmosphériques) databases. In Sect. 2, a discussion of previous HCFC-22 IR absorption cross-section datasets, derived from laboratory measurements, is presented. Section 3 provides details on the new measurements taken as part of this work and the derivation of cross sections, with Sect. 4 providing a discussion of the results and comparison with previous measurements.

\section{Previous quantitative spectroscopic measurements of chlorodifluoromethane}

There are two principal chlorodifluoromethane isotopologues, $\mathrm{CH}^{35} \mathrm{ClF}_{2}$ and $\mathrm{CH}^{37} \mathrm{ClF}_{2}$, with abundances of $\sim 76$ and $\sim 24 \%$, respectively. Both isotopologues are asymmetric tops belonging to the $C_{s}$ point group, and each possess a single plane of symmetry $(\mathrm{CHCl})$ containing the $a$ and $c$ principal axes. Chlorodifluoromethane has nine fundamental vibrational modes; six $\left(v_{1}-v_{6}\right)$ are symmetric $\left(\mathrm{A}^{\prime}\right)$ with respect to the symmetry plane, appearing as $a / c$-type bands in the IR, and three $\left(\nu_{7}-v_{9}\right)$ are antisymmetric $\left(\mathrm{A}^{\prime \prime}\right)$ with respect to the symmetry plane, corresponding to $b$-type bands (Snels and D'Amico, 2001).

The $730-1380 \mathrm{~cm}^{-1}$ spectral range covered in the present work contains a number of strong band systems: the fundamental $v_{4} \sim 804.5 \mathrm{~cm}^{-1}\left(\mathrm{CH}^{37} \mathrm{ClF}_{2}\right) / 809.3 \mathrm{~cm}^{-1}$ $\left(\mathrm{CH}^{35} \mathrm{ClF}_{2}\right)$ (Ross et al., 1989) in Fermi resonance with the overtone $2 v_{6} \sim 820.9 \quad\left(\mathrm{CH}^{37} \mathrm{ClF}_{2}\right) / 829.1$ $\left(\mathrm{CH}^{35} \mathrm{ClF}_{2}\right)$ (Ross et al., 1989), and Coriolis-coupled doublets $\nu_{3} \sim 1108.7 \mathrm{~cm}^{-1}$ and $\nu_{8} \sim 1127.1 \mathrm{~cm}^{-1}$ $\left(\mathrm{CH}^{37} \mathrm{ClF}_{2}\right) / 1127.3 \mathrm{~cm}^{-1} \quad\left(\mathrm{CH}^{35} \mathrm{ClF}_{2}\right) \quad($ Snels and D'Amico, 2001), and $v_{2} \sim 1312.9 \mathrm{~cm}^{-1}\left(\mathrm{CH}^{37} \mathrm{ClF}_{2}\right) / 1313.1$ $\left(\mathrm{CH}^{35} \mathrm{ClF}_{2}\right)$ and $\nu_{7} \sim 1351.7 \mathrm{~cm}^{-1}$ (Thompson et al., 2002). Figure 1 provides a plot of the new absorption cross section at $270.0 \mathrm{~K}$ and 7.51 Torr with these main band systems labelled. Note that the $v_{4}$ and $2 v_{6}$ Q branches associated with each isotopologue are easily identified in Fig. 1. Full details on the measurement conditions and derivation of this cross section are given in Sect. 3 .

The first published absolute intensities of chlorodifluoromethane IR bands were those of Varanasi and Chudamani (1988); however it was several years later before absorption cross sections appeared (McDaniel et al., 1991). Derived from measurements of pure chlorodifluoromethane at $0.03 \mathrm{~cm}^{-1}$ resolution and 203,213,233, 253,273, and $293 \mathrm{~K}\left(780-1335 \mathrm{~cm}^{-1}\right)$, these cross sections were subsequently incorporated into the HITRAN 1992 compilation (Rothman et al., 1992; Massie and Goldman, 1992). $\mathrm{N}_{2-}$ broadened chlorodifluoromethane absorption cross sections for the bands between 700 and $1400 \mathrm{~cm}^{-1}$, derived from measurements over a range of temperatures down to $200 \mathrm{~K}$ at a spectral resolution of $0.03 \mathrm{~cm}^{-1}$, were subsequently pub- 


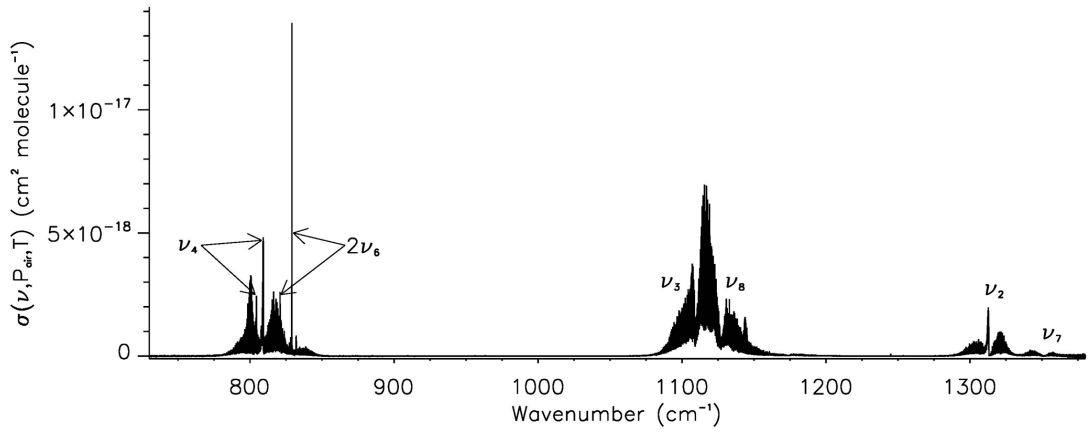

Figure 1. The IR absorption cross section of chlorodifluoromethane/dry synthetic air at $270.0 \mathrm{~K}$ and 7.51 Torr, with vibrational band assignments for the main band systems covered in this work. Note that the arrows associated with $v_{4}$ and $2 v_{6}$ indicate the Q branches associated with each isotopologue, with that for the more abundant $\mathrm{CH}^{35} \mathrm{ClF}_{2}$ at higher wavenumber than $\mathrm{CH}^{37} \mathrm{ClF}_{2}$.

lished by Varanasi et al. (1994). Seven of these PT combinations, over the range $760-860 \mathrm{~cm}^{-1}$ with temperatures ranging from 216 to $294 \mathrm{~K}$ and pressures from 40 to 760 Torr, were included in the HITRAN 1996 compilation (Rothman et al., 1998).

The chlorodifluoromethane cross sections were given an overhaul for HITRAN 2000 (Rothman et al., 2003); the database now contained nine cross sections $\left(0.03 \mathrm{~cm}^{-1}\right.$ resolution) from Clerbaux et al. (1993) for pure samples at three temperatures $(287,270$ and $253 \mathrm{~K})$ and three wavenumber ranges $\left(760-860,1060-1210\right.$, and $\left.1275-1380 \mathrm{~cm}^{-1}\right)$, and 57 from Varanasi (personal communication (2000) in Rothman et al., 2003) over the range $181-297 \mathrm{~K}$ and $21-761$ Torr, 26 of these covering $760-860 \mathrm{~cm}^{-1}$ and the remaining 31 covering 1070-1195 $\mathrm{cm}^{-1}$; note that this dataset does not cover the $v_{2}$ and $v_{7}$ bands. Whereas the Clerbaux dataset (Clerbaux et al., 1993) is not particularly useful for atmospheric remote-sensing applications because it does not cover an appropriate range of atmospheric temperatures and pressures, the Varanasi dataset has been used extensively for such applications over the last decade and a half. This dataset has remained unchanged for subsequent HITRAN compilations, including the most recent HITRAN 2012 (Rothman et al., 2013), and has additionally been included in the most recent GEISA 2003 (Jacquinet-Husson et al., 2005) and 2009 (Jacquinet-Husson et al., 2011) compilations, although in GEISA there are 51 cross-section files, six of which cover both spectral regions. Despite its widespread use, the Varanasi dataset has a number of deficiencies which will be fully discussed in Sect. 4 .

\section{New absorption cross sections of air-broadened chlorodifluoromethane}

\subsection{Experimental}

The experimental set-up has been used previously for related measurements (e.g. Harrison et al., 2010; Harrison, $2015 b$ ), so only a summary is provided here. All air- broadened chlorodifluoromethane IR spectra were recorded at the Molecular Spectroscopy Facility (MSF), Rutherford Appleton Laboratory (RAL), using a Bruker Optics IFS 125 HR FTS, and an internally mounted $26 \mathrm{~cm}$ pathlength sample cell connected to a Julabo F95-SL Ultra-Low Refrigerated Circulator filled with ethanol. Sample mixtures were prepared by introducing chlorodifluoromethane (Asahi Glass Company, $>99 \%$ purity, natural-abundance isotopic mixture, used "as is") directly into the cell and then adding dry synthetic air ("Air Zero", supplied by BOC); between measurements the cell was evacuated to $<0.001$ Torr. Mixture pressures were measured close to the cell inlet using Baratron capacitance manometers (MKS), and the cell temperature was monitored by four platinum resistance thermometers (PRTs) in thermal contact at different points on the exterior surface of the cell; for the majority of measurements the temperature gradient within the cell was below $0.5 \mathrm{~K}$, although this was closer to $1.0 \mathrm{~K}$ at the lowest temperatures. Spectra were recorded at resolutions between 0.01 and $0.03 \mathrm{~cm}^{-1}$ (defined as the Bruker instrument resolution of $0.9 / \mathrm{MOPD}$; MOPD denotes the maximum optical path difference), a similar range to those of the Varanasi measurements, $0.01 \mathrm{~cm}^{-1}$ resolution for the lowest pressures (in the Doppler-limited regime), and $0.03 \mathrm{~cm}^{-1}$ for the highest pressures. The FTS instrumental parameters and settings are summarised in Table 1, with sample pressures, temperatures, and their experimental uncertainties and associated spectral resolutions listed in Table 2. Multiple interferograms were recorded at each PT combination in order to improve the signal-to-noise, with empty cell background interferograms recorded before and after these sample measurements. Pure nitrous oxide $\left(\mathrm{N}_{2} \mathrm{O}\right)$ spectra were additionally recorded at each temperature to calibrate the wavenumber scale of the air-broadened chlorodifluoromethane spectra. 
Table 1. FTS parameters and cell configuration for all measurements.

\begin{tabular}{ll}
\hline Mid-IR source & Globar \\
Detector & Mercury cadmium telluride (MCT) D313 ${ }^{\mathrm{a}}$ \\
Beam splitter & Potassium bromide (KBr) \\
Optical filter & $\sim 700-1700 \mathrm{~cm}^{-1}$ bandpass \\
Spectral resolution & 0.01 to $0.03 \mathrm{~cm}^{-1}$ \\
Aperture size & $3.15 \mathrm{~mm}$ \\
Apodisation function & Boxcar \\
Phase correction & Mertz \\
Cell windows & Potassium bromide (KBr) (wedged) \\
Pressure gauges & Three MKS-690A Baratrons $(1,10$ and 1000 Torr) $( \pm 0.05 \%$ accuracy) \\
Thermometry & Four PRTs, Labfacility IEC 751 Class A \\
\hline
\end{tabular}

${ }^{a}$ Due to the non-linear response of MCT detectors to the detected radiation, all interferograms were Fourier transformed using Bruker's OPUS software with a non-linearity correction applied.

Table 2. Summary of the sample conditions for all measurements.

\begin{tabular}{|c|c|c|c|}
\hline Temperature (K) & $\begin{array}{c}\text { Initial } \mathrm{CHClF}_{2} \\
\text { pressure }(\mathrm{Torr})^{\mathrm{a}}\end{array}$ & Total pressure (Torr) & $\begin{array}{l}\text { Spectral resolution } \\
\left(\mathrm{cm}^{-1}\right)^{\mathrm{b}}\end{array}$ \\
\hline $190.9 \pm 0.5$ & 0.1440 & $7.496 \pm 0.008$ & 0.0100 \\
\hline $190.8 \pm 0.5$ & 0.1875 & $50.75 \pm 0.08$ & 0.0150 \\
\hline $190.8 \pm 0.5$ & 0.1984 & $99.50 \pm 0.23$ & 0.0150 \\
\hline $190.8 \pm 0.5$ & 0.3018 & $199.2 \pm 0.4$ & 0.0225 \\
\hline $201.5 \pm 0.4$ & 0.1566 & $7.507 \pm 0.030$ & 0.0100 \\
\hline $201.5 \pm 0.4$ & 0.1902 & $52.51 \pm 0.15$ & 0.0150 \\
\hline $201.4 \pm 0.4$ & 0.2027 & $100.6 \pm 0.7$ & 0.0150 \\
\hline $201.4 \pm 0.4$ & 0.3377 & $200.0 \pm 0.2$ & 0.0225 \\
\hline $201.4 \pm 0.4$ & 0.3267 & $302.5 \pm 0.7$ & 0.0300 \\
\hline $216.3 \pm 0.1$ & 0.1721 & $7.570 \pm 0.005$ & 0.0100 \\
\hline $216.3 \pm 0.1$ & 0.2066 & $50.83 \pm 0.11$ & 0.0150 \\
\hline $216.3 \pm 0.1$ & 0.2280 & $100.6 \pm 0.1$ & 0.0150 \\
\hline $216.3 \pm 0.1$ & 0.3851 & $200.6 \pm 0.2$ & 0.0225 \\
\hline $216.3 \pm 0.1$ & 0.3862 & $349.5 \pm 0.2$ & 0.0300 \\
\hline $232.7 \pm 0.1$ & 0.1857 & $7.500 \pm 0.002$ & 0.0100 \\
\hline $232.8 \pm 0.1$ & 0.2229 & $50.07 \pm 0.02$ & 0.0150 \\
\hline $232.7 \pm 0.1$ & 0.3288 & $100.3 \pm 0.0$ & 0.0150 \\
\hline $232.7 \pm 0.1$ & 0.4769 & $201.9 \pm 0.1$ & 0.0225 \\
\hline $232.7 \pm 0.1$ & 0.4800 & $399.9 \pm 0.1$ & 0.0300 \\
\hline $251.2 \pm 0.2$ & 0.2571 & $7.523 \pm 0.023$ & 0.0100 \\
\hline $251.2 \pm 0.2$ & 0.3683 & $50.82 \pm 0.04$ & 0.0150 \\
\hline $251.2 \pm 0.2$ & 0.4594 & $204.9 \pm 0.1$ & 0.0225 \\
\hline $251.2 \pm 0.2$ & 0.6050 & $400.2 \pm 0.1$ & 0.0300 \\
\hline $251.2 \pm 0.2$ & 0.6469 & $602.6 \pm 0.2$ & 0.0300 \\
\hline $270.0 \pm 0.2$ & 0.2858 & $7.514 \pm 0.045$ & 0.0100 \\
\hline $270.0 \pm 0.2$ & 0.5317 & $201.5 \pm 0.0$ & 0.0225 \\
\hline $269.9 \pm 0.1$ & 0.6917 & $352.2 \pm 0.0$ & 0.0300 \\
\hline $269.9 \pm 0.1$ & 0.9080 & $759.9 \pm 0.2$ & 0.0300 \\
\hline $294.5 \pm 0.1$ & 0.8388 & $351.4 \pm 0.1$ & 0.0300 \\
\hline $294.8 \pm 0.1$ & 1.0162 & $761.6 \pm 0.5$ & 0.0300 \\
\hline
\end{tabular}

${ }^{\mathrm{a}}$ MKS-690A Baratron readings are accurate to $\pm 0.05 \%{ }^{\mathrm{b}}$ Using the Bruker definition of 0.9/MOPD. 


\subsection{Determination of absorption cross sections for chlorodifluoromethane}

The procedure for generating absorption cross sections from the experimental data is identical to that reported previously (e.g. Harrison et al., 2010; Harrison, 2015b). A Fourier transform algorithm was applied to measured interferograms using Bruker's OPUS software, and transmittance spectra calculated directly as $I_{\text {sample }} / I_{\text {background }}$. Wavenumbers were calibrated against the positions of isolated $\mathrm{N}_{2} \mathrm{O}$ absorption lines in the range 1140 to $1320 \mathrm{~cm}^{-1}$, taken from the HITRAN 2012 database (Rothman et al., 2013).

Initial absorption cross sections were derived via the Beer-Lambert law, which relates the transmittance, $\tau(v$, $\left.P_{\text {air }}, T\right)$, at wavenumber $v\left(\mathrm{~cm}^{-1}\right)$, temperature $T(\mathrm{~K})$, and synthetic air pressure $P_{\text {air }}$, to the absorption cross section, $\sigma\left(v, P_{\text {air }}, T\right)$, with units $\mathrm{cm}^{2}$ molecule ${ }^{-1}$, by

$\sigma\left(v, P_{\mathrm{air}}, T\right)=-\frac{10^{4} k_{\mathrm{B}} T}{P l} \ln \tau\left(v, P_{\mathrm{air}}, T\right)$,

where $P$ is the pressure of the absorbing gas $(\mathrm{Pa}), l$ is the optical pathlength (m), and $k_{\mathrm{B}}$ is the Boltzmann constant (i.e. $\left.1.3806488 \times 10^{-23} \mathrm{~J} \mathrm{~K}^{-1}\right)$.

During the experimental work, evidence was found for chlorodifluoromethane adsorption in the vacuum line and on the cell walls, resulting in its partial pressure during each measurement differing from the initial, measured value, although there was no evidence for this partial pressure changing over the course of a scan. This confirms previous observations made during the Spectroscopy and Warming potentials of Atmospheric Greenhouse Gases (SWAGG) project, which focused only on spectroscopic measurements for radiative forcing and global warming potentials rather than for remote sensing (Ballard et al., 2000). Due to this adsorption, the initial cross sections derived from Eq. (1) needed to be calibrated against a "calibration standard" integrated band strength. This assumes that the integrated intensity over each band system is independent of temperature. The reader is referred to the discussion in Harrison et al. (2010) for a more complete explanation of the underlying assumption, and references cited within Harrison (2015a) for details on the successful use of this approach in the past.

Integrated band strengths were calculated over the range $730-1265 \mathrm{~cm}^{-1}$ for each of these cross sections, and ratios taken against a calibration standard integrated band strength over the same spectral range, derived from two 760 Torr- $\mathrm{N}_{2}$ broadened chlorodifluoromethane spectra (recorded at 278 and $298 \mathrm{~K}$ ) from the Pacific Northwest National Laboratory (PNNL) IR database (http://nwir.pnl.gov) (Sharpe et al., 2004). Final absorption cross sections were obtained by calibrating the $y$ axis, i.e. multiplying each cross section from Eq. (1) by the calibration factor $\xi$, given by

$$
\xi=\frac{9.3554 \times 10^{-17} \mathrm{~cm} \text { molecule }}{-1} .
$$

Note that each PNNL spectrum, recorded at $0.112 \mathrm{~cm}^{-1}$ spectral resolution, is a composite of multiple pathlengthconcentration burdens, and great care has been taken to ensure that sample concentrations have been determined accurately; systematic errors are $\sim 1.5 \%(1 \sigma)$.

The wavenumber accuracy of the new absorption cross sections is comparable to the accuracy of the $\mathrm{N}_{2} \mathrm{O}$ lines used in the calibration; HITRAN error codes indicate this is between 0.001 and $0.0001 \mathrm{~cm}^{-1}$. In order to obtain an estimate of the $y$ axis random errors, many measurements should be taken at each PT combination. Due to time constraints, however, only one spectrum has been recorded for each of these combinations, in the same manner as the Varanasi dataset. Despite this, it is expected that systematic errors make the dominant contribution to the uncertainty. Maximum uncertainties in the sample temperatures $\left(\mu_{\mathrm{T}}\right)$ and total pressures $\left(\mu_{\mathrm{P}}\right)$ are 0.3 and $0.7 \%$, respectively (Table 2 ). The photometric uncertainty $\left(\mu_{\mathrm{phot}}\right)$ is estimated to be $\sim 2 \%$. The pathlength error $\left(\mu_{\text {path }}\right)$ is estimated to be negligibly small, lower than $0.1 \%$. According to the relevant metadata files in the PNNL database, the systematic error in the PNNL chlorodifluoromethane spectra used for intensity calibration is estimated to be $\leq 3 \%(2 \sigma)$. Equating the error, $\mu_{\mathrm{PNNL}}$, with the maximum $1 \sigma$ value, i.e. $1.5 \%$, and assuming that the error estimates for all quantities are uncorrelated, the overall systematic error in the dataset can be calculated from

$\mu_{\text {systematic }}^{2}=\mu_{\mathrm{PNNL}}^{2}+\mu_{\mathrm{T}}^{2}+\mu_{\mathrm{P}}^{2}+\mu_{\mathrm{phot}}^{2}$.

Note that using PNNL spectra for intensity calibration effectively nullifies the errors in the chlorodifluoromethane partial pressures and cell pathlength, so these do not have to be included in Eq. (3). According to Eq. (3), the systematic error contribution, $\mu_{\text {systematic }}$, to the new cross sections is $\sim 3 \%$ $(1 \sigma)$.

\section{Discussion and comparison of absorption cross-section datasets}

This section outlines the improvements in the new absorption cross-section dataset in relation to the previous Varanasi dataset. A numerical quantification of how the new cross sections improve atmospheric retrievals is beyond the scope of this work. These new cross sections will be used for the upcoming ACE-FTS version 4.0 processing (C. D. Boone, personal communication, 2015), and a more detailed investigation will follow. 


\subsection{Signal-to-noise ratios (SNRs)}

The SNRs of the new transmittance spectra, calculated using Bruker's OPUS software at $\sim 990 \mathrm{~cm}^{-1}$ where the transmittance is close to 1 , range from 1300 to 2500 (root mean square). Without access to the original Varanasi transmittance spectra and without knowledge of the absorber partial pressures, it is not possible to determine the same quantity for the Varanasi measurements. A direct comparison between the absorption cross-section datasets reveals the new cross sections represent an overall improvement in SNR.

\subsection{Channel fringing}

The majority of the Varanasi cross sections, principally those derived from $0.01 \mathrm{~cm}^{-1}$ resolution spectra at low $P$ and $T$, contain channel fringes noticeably above the noise level, likely equating with peak-to-peak amplitudes of $\sim 2-3 \%$ in transmittance for the original Varanasi measurements; these are caused by reflections from windows etc. in the optical path of the spectrometer. For the measurements described in the present work, channel fringes have been avoided by using wedged cell windows.

\subsection{Integrated band strengths}

In order to compare integrated band strengths of the new absorption cross sections with those of Varanasi, integrals have been calculated over the spectral ranges of the Varanasi cross-section files in HITRAN, 760-860 and 1070$1195 \mathrm{~cm}^{-1}$, covering principally the $v_{4} / 2 v_{6}$ and $v_{3} / v_{8}$ bands respectively. There are a number of instances of baseline inconsistencies in the Varanasi cross sections, e.g. shifts or changes in slope, and the cross sections provided via both the HITRAN and GEISA databases have had all negative $y$ values set to zero; these issues will all contribute to systematic errors in the Varanasi integrated band strengths. Figure 2 provides a plot of integrated band strength (without error bars, for ease of viewing) against temperature for each dataset and wavenumber range. The Varanasi integrated band strengths display a small spread in values, with a good deal more scatter for the $v_{3} / v_{8}$ bands; however there is no evidence for any temperature dependence, as expected.

\subsection{Wavenumber calibration}

There is no mention of wavenumber calibration in the initial publication of Varanasi et al. (1994); however the HITRAN 2000 publication (Rothman et al., 2003) states that the wavenumber scales were calibrated using the absorption lines of ammonia, acetylene, carbon dioxide, methane, and nitrous oxide bands in the thermal IR (7-14 $\mu \mathrm{m})$ as given in HITRAN. Despite this, the wavenumber scale does not agree with that determined for the new dataset, and there is some variation in this scale from cross section to cross section. Figure 3 provides a plot of the new cross section at $201.5 \mathrm{~K}$

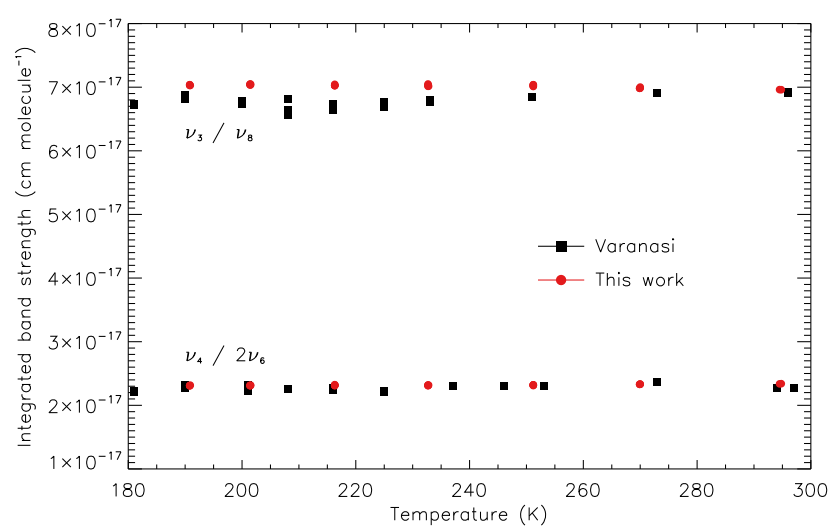

Figure 2. A plot of integrated band strength vs. temperature for each of the datasets over the wavenumber ranges $760-860 \mathrm{~cm}^{-1}$ (principally the $v_{4}$ and $2 v_{6}$ bands; bottom) and $1070-1195 \mathrm{~cm}^{-1}$ (principally the $v_{3}$ and $v_{8}$ bands; top). The Varanasi data at each temperature display a small spread in values, with a good deal more scatter in the $v_{3} / v_{8}$ band strengths, likely due to some systematic error in the measurements.

and 52.51 Torr, with the difference relative to a re-baselined and re-normalised Varanasi cross section (at $201.0 \mathrm{~K}$ and 50.4 Torr) plotted underneath (new - old). The difference plot reveals a number of sharp features, particularly the one at $\sim 829.05 \mathrm{~cm}^{-1}$, which coincides with the sharp $2 v_{6} \mathrm{Q}$ branch of the $\left(\mathrm{CH}^{35} \mathrm{ClF}_{2}\right)$ isotopologue. Although there are small differences in the measurement of $P, T$, and intensity between the two cross sections, the systematic features in the differences result almost entirely from the poor wavenumber scale of the Varanasi cross section, which in this spectral region is shifted too low by $\sim 0.0045 \mathrm{~cm}^{-1}$ (a correction factor of $\sim 1.000005$ ). This is in line with the wavenumber calibration errors observed for previous Varanasi HFC-134a (Harrison, 2015a) and CFC-12 (Harrison, 2015b) datasets.

\subsection{Pressure-temperature coverage}

A retrieval scheme in which the forward model uses absorption cross sections should ideally interpolate between cross sections rather than extrapolate beyond them. The target $P$ and $T$ of an atmospheric spectrum should be bracketed with four cross sections, two of these at higher $T$, two at lower $T$, and one each of these at lower and higher $P$. This means that the PT combinations within the dataset must cover all possible combinations of pressure and temperature appropriate for the region of the atmosphere being observed. Figure 4 provides a graphical representation of the PT combinations for both datasets. It is readily observed that the Varanasi dataset does not cover a wide enough range of pressures and temperatures for the successful implementation of a four-point interpolation scheme. Note, for example, that above $225 \mathrm{~K}$ the very strong $2 v_{6} \mathrm{Q}$ branch $\left(\mathrm{CH}^{35} \mathrm{ClF}_{2}\right)$ is covered by only six absorption cross sections, each at a different temperature; 


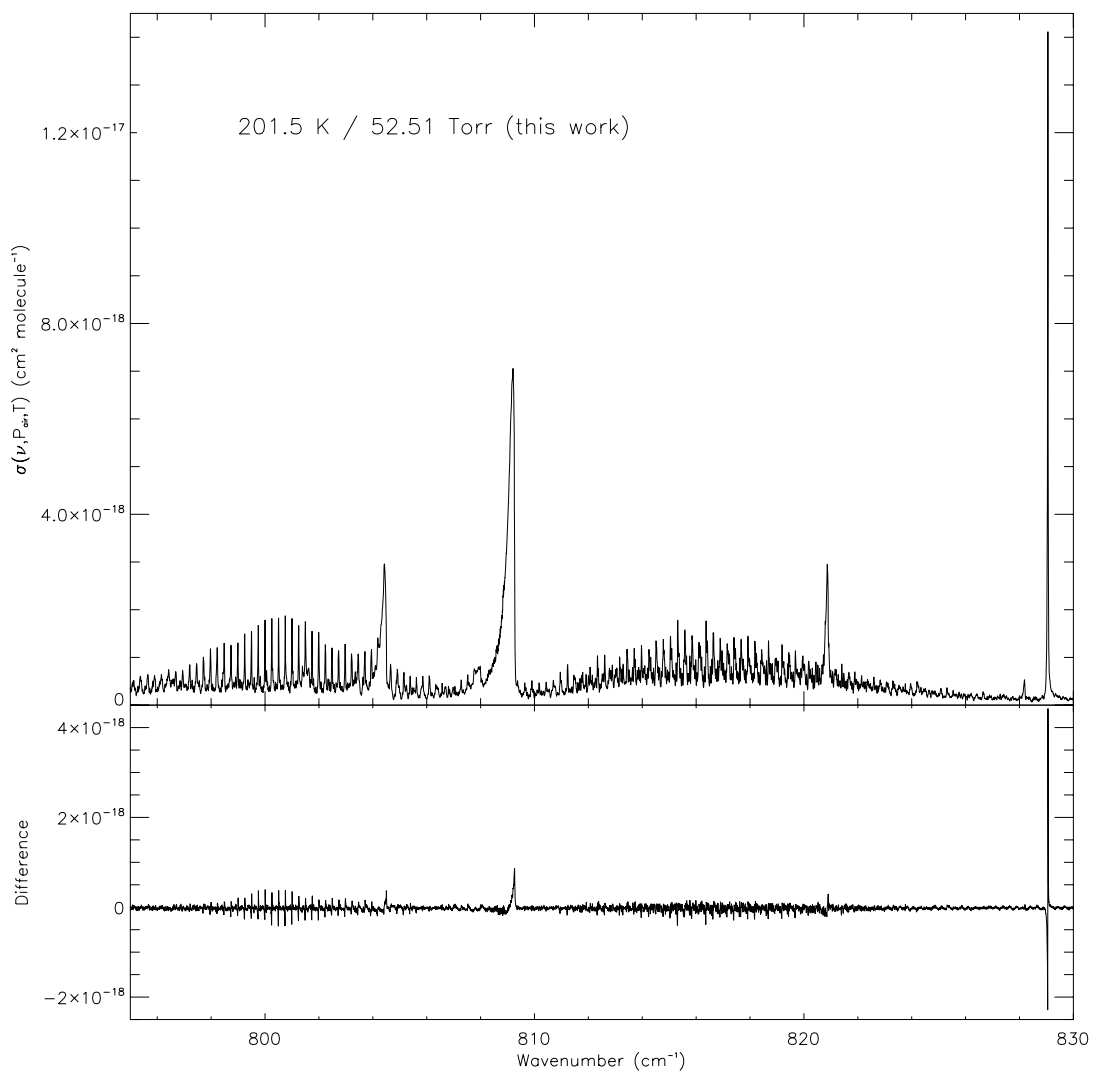

Figure 3. Top: the new IR absorption cross section of chlorodifluoromethane/dry synthetic air at $201.5 \mathrm{~K}$ and 52.51 Torr, covering part of the $v_{4}$ and $2 v_{6}$ bands. Bottom: the difference between the new cross section and the re-baselined and re-normalised Varanasi cross section at 201.0 K and 50.4 Torr (new - old). The observed features in the difference plot are indicative of poor wavenumber calibration in the Varanasi cross section.

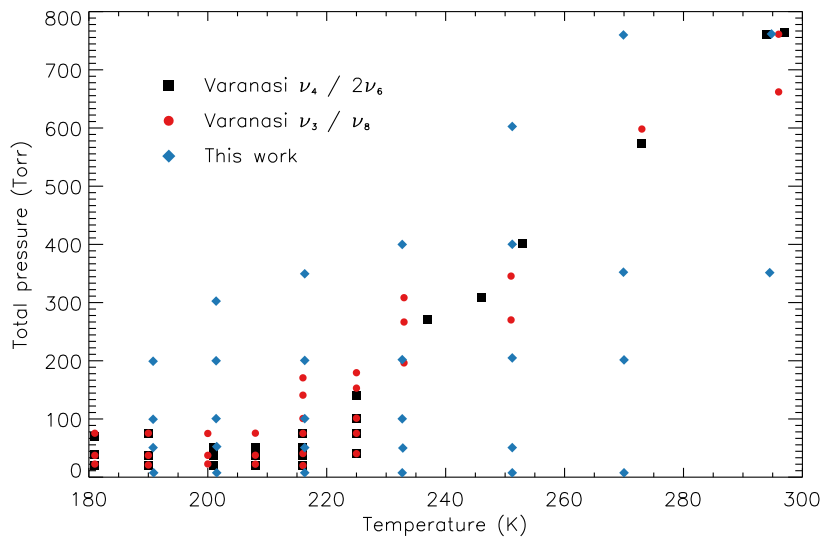

Figure 4. A graphical representation of the PT coverage for both the new and Varanasi datasets. Although the new dataset contains fewer individual IR absorption cross sections (30), it has been optimised to provide a more balanced dataset with wider PT coverage.

this would necessarily result in errors in retrieved HCFC-22 mixing ratios. The new dataset presented in this work has extended the PT coverage (30 PT combinations in total) to resolve this problem. However, it was not possible to record spectra at temperatures below $191 \mathrm{~K}$ with the Julabo F95-SL Ultra-Low Refrigerated Circulator used in this work.

\section{Conclusions}

New high-resolution IR absorption cross sections for airbroadened chlorodifluoromethane have been determined over the spectral range $730-1380 \mathrm{~cm}^{-1}$, with an estimated uncertainty of $3 \%(1 \sigma)$. Spectra were recorded for mixtures of chlorodifluoromethane with dry synthetic air in a $26 \mathrm{~cm}$ pathlength cell at spectral resolutions between 0.01 and $0.03 \mathrm{~cm}^{-1}$ (calculated as $0.9 / \mathrm{MOPD}$ ) over a range of temperatures and pressures appropriate for upper troposphere - lower stratosphere conditions (7.5-762 Torr and 191-295 K). Intensities were calibrated against chlorodifluoromethane spectra in the PNNL IR database. These new cross sections improve upon those currently available in the HITRAN and GEISA databases (Varanasi et al., 1994; Rothman et al., 2003); in particular they cover a wider range of pressures and temperatures, have more accurately calibrated wavenumber scales, have more consistent integrated band intensities, exhibit no discernible channel fringing, possess 
improved SNR, and additionally cover the $v_{2}$ and $v_{7}$ bands. This dataset will provide a more accurate basis for retrieving HCFC-22 abundances from atmospheric IR spectra recorded by remote-sensing instruments.

\section{Data availability}

The new HCFC-22 dataset is available electronically from the author and will be made available to the community via the HITRAN and GEISA databases.

Acknowledgements. The author wishes to thank the National Centre for Earth Observation (NCEO), funded by the UK Natural Environment Research Council (NERC), for supporting this work and for access to the Molecular Spectroscopy Facility (MSF) at the Rutherford Appleton Laboratory (RAL), R. G. Williams and R. A. McPheat for providing technical support at the RAL, and J. J. Remedios for assistance in accessing the MSF.

Edited by: L. Hoffmann

\section{References}

Ballard, J., Knight, R. J., Newnham, D. A., Vander Auwera, J., Herman, M., Di Lonardo, G., Masciarelli, G., Nicolaisen, F. M., Beukes, J. A., Christensen, L. K., Mcpheat, R., Duxbury, G., Freckleton, R., and Shine, K. P.: An intercomparison of laboratory measurements of absorption cross-sections and integrated absorption intensities for HCFC-22, J. Quant. Spectrosc. Ra., 66, 109-128, doi:10.1016/S0022-4073(99)00211-3, 2000.

Brown, A. T., Chipperfield, M. P., Boone, C., Wilson, C., Walker, K. A., and Bernath, P. F.: Trends in atmospheric halogen containing gases since 2004, J. Quant. Spectrosc. Ra., 112, 2552-2566, 2011

Carpenter, L. J., Reimann, S., Burkholder, J .B., Clerbaux, C., Hall, B. D., Hossaini, R., Laube, J. C., and Yvon-Lewis, S. A.: OzoneDepleting Substances (ODSs) and Other Gases of Interest to the Montreal Protocol, Chapter 1 in Scientific Assessment of Ozone Depletion: 2014, Global Ozone Research and Monitoring Project - Report No. 55, World Meteorological Organization, Geneva, Switzerland, 2014.

Clerbaux, C., Colin, R., Simon, P. C., and Granier, C.: Infrared cross sections and global warming potentials of 10 alternative hydrohalocarbons, J. Geophys. Res., 98, 10491-10497, 1993.

Harris, N. R. P., Wuebbles, D. J., Daniel, J. S., Hu, J., Kuijpers, L. J. M., Law, K. S., Prather, M. J., and Schofield, R.: Scenarios and information for policymakers, Chapter 5 in Scientific Assessment of Ozone Depletion: 2014, Global Ozone Research and Monitoring Project - Report No. 55, World Meteorological Organization, Geneva, Switzerland, 2014.

Harrison, J. J.: Infrared absorption cross sections for 1,1,1,2tetrafluoroethane, J. Quant. Spectrosc. Ra., 151, 210-216, doi:10.1016/j.jqsrt.2014.09.023, 2015a.

Harrison, J. J.: New and improved infrared absorption cross sections for dichlorodifluoromethane (CFC-12), Atmos. Meas. Tech., 8, 3197-3207, doi:10.5194/amt-8-3197-2015, 2015 b.
Harrison, J. J., Allen, N. D. C., and Bernath, P. F.: Infrared absorption cross sections for ethane $\left(\mathrm{C}_{2} \mathrm{H}_{6}\right)$ in the $3 \mu \mathrm{m}$ region, $\mathrm{J}$. Quant. Spectrosc. Ra., 111, 357-363, 2010.

Harrison, J. J., Boone, C. D., Brown, A. T., Allen, N. D. C., Toon, G. C., and Bernath, P. F.: First remote sensing observations of trifluoromethane (HFC-23) in the upper troposphere and lower stratosphere, J. Geophys. Res., 117, D05308, doi:10.1029/2011JD016423, 2012.

Irion, F. W., Gunson, M. R., Toon, G. C., Chang, A. Y., Eldering, A., Mahieu, E., Manney, G. L., Michelsen, H. A., Moyer, E. J., Newchurch, M. J., Osterman, G. B., Rinsland, C. P., Salawitch, R. J., Sen, B., Yung, Y. L., and Zander, R.: Atmospheric Trace Molecule Spectroscopy (ATMOS) Experiment Version 3 data retrievals, Appl. Optics, 41, 6968-6979, 2002.

Jacquinet-Husson, N., Scott, N. A., Chédin, A., Garceran, K., Armante, R., Chursin, A. A., Barbe, A., Birk, M., Brown, L. R., Camy-Peyret, C., Claveau, C., Clerbaux, C., Coheur, P. F., Dana, V., Daumont, L., Debacker-Barilly, M. R., Flaud, J. M., Goldman, A., Hamdouni, A., Hess, M., Jacquemart, D., Köpke, P., Mandin, J. Y., Massie, S., Mikhailenko, S., Nemtchinov, V., Nikitin, A., Newnham, D., Perrin, A., Perevalov, V. I., RégaliaJarlot, L., Rublev, A., Schreier, F., Schult, I., Smith, K. M., Tashkun, S. A., Teffo, J. L., Toth, R. A., Tyuterev, Vl. G., Vander Auwera, J., Varanasi, P., and Wagner, G.: The 2003 edition of the GEISA/IASI spectroscopic database, J. Quant. Spectrosc. Ra. 95, 429-467, 2005.

Jacquinet-Husson, N., Crepeau, L., Armante, R., Boutammine, C., Chédin, A., Scott, N. A., Crevoisier, C., Capelle, V., Boone, C., Poulet-Crovisier, N., Barbe, A., Campargue, A., Benner, D. C., Benilan, Y., Bézard, B., Boudon, V., Brown, L. R., Coudert, L. H., Coustenis, A., Dana, V., Devi, V. M., Fally, S., Fayt, A., Flaud, J.-M., Goldman, A., Herman, M., Harris, G. J., Jacquemart, D., Jolly, A., Kleiner, I., Kleinböhl, A., Kwabia-Tchana, F., Lavrentieva, N., Lacome, N., Xu, L.-H., Lyulin, O.M., Mandin, J.-Y., Maki, A., Mikhailenko, S., Miller, C.E., Mishina, T., Moazzen-Ahmadi, N., Müller, H. S. P., Nikitin, A., Orphal, J., Perevalov, V., Perrin, A., Petkie, D. T., Predoi-Cross, A., Rinsland, C. P., Remedios, J. J., Rotger, M., Smith, M. A. H., Sung, K., Tashkun, S., Tennyson, J., Toth, R. A., Vandaele, A.-C., and Vander Auwera, J.: The 2009 edition of the GEISA spectroscopic database, J. Quant. Spectrosc. Ra., 112, 2395-2445, 2011.

Massie, S. T. and Goldman, A.: Absorption parameters of very dense molecular spectra for the HITRAN compilation, J. Quant. Spectrosc. Ra., 48, 713-719, 1992.

McDaniel, A. H., Cantrell, C. A., Davidson, J. A., Shetter, R. E., and Calvert, J. G.: The Temperature Dependent, Infrared Absorption Cross-Sections for the Chlorofluorocarbons: CFC-11, CFC-12, CFC-13, CFC-14, CFC-22, CFC-113, CFC-114, and CFC-115, J. Atmos. Chem., 12, 211-227, 1991.

Moore, D. P. and Remedios, J. J.: Growth rates of stratospheric HCFC-22, Atmos. Chem. Phys., 8, 73-82, doi:10.5194/acp-873-2008, 2008.

Myers, R. L.: The 100 most important chemical compounds: a reference guide, Greenwood Press, Westport, Connecticut, USA, 2007.

Ross, A. J., Amrein, A., Luckhaus, D., and Quack, M.: The rotational structure of the $v_{4}$ band of $\mathrm{CH}^{35} \mathrm{ClF}_{2}$, Mol. Phys., 66, 1273-1277, 1989. 
Rothman, L. S., Gamache, R. R., Tipping, R. H., Rinsland, C. P., Smith, M. A. H., Benner D. C., Devi, V. M, Flaud, J.-M., CamyPeyret, C., Perrin, A., Goldman, A., Massie, S. T., Brown, L. R., and Toth, R. A.: The HITRAN molecular database: Editions of 1991 and 1992, J. Quant. Spectrosc. Ra., 48, 469-507, 1992.

Rothman, L. S., Rinsland, C. P., Goldman, A., Massie, S. T., Edwards, D. P., Flaud, J.-M., Perrin, A., Camy-Peyret, C., Dana, V., Mandin, J.-Y., Schroeder, J., Mccann, A., Gamache, R. R., Wattson, R. B., Yoshino, K., Chance, K. V., Jucks, K. W., Brown, L. R., Nemtchinov, V., and Varanasi, P.: The HITRAN Molecular Spectroscopic Database and Hawks (HITRAN Atmospheric Workstation): 1996 Edition, J. Quant. Spectrosc. Ra., 60, 665710,1998

Rothman, L. S., Barbe, A., Benner, D. C., Brown, L. R., CamyPeyret, C., Carleer, M. R., Chance, K., Clerbaux, C., Dana, V., Devi, V. M., Fayt, A., Flaud, J.-M., Gamache, R. R., Goldman, A., Jacquemart, D., Jucks, K. W., Lafferty, W. J., Mandin, J.-Y., Massie, S. T., Nemtchinov, V., Newnham, D. A., Perrin, A., Rinsland, C. P., Schroeder, J., Smith, K. M., Smith, M. A. H., Tang, K., Toth, R. A., Vander Auwera, J., Varanasi, P., and Yoshino, K.: The HITRAN molecular spectroscopic database: Edition of 2000 including updates through 2001, J. Quant. Spectrosc. Ra., 82, 5-44, 2003.

Rothman, L. S., Gordon, I. E., Babikov, Y., Barbe, A., Benner, D. C., Bernath, P. F., Birk, M., Bizzocchi, L., Boudon, V., Brown, L. R., Campargue, A., Chance, K., Cohen, E. A., Coudert, L. H., Devi, V. M., Drouin, B. J., Fayt, A., Flaud, J.-M., Gamache, R. R., Harrison, J. J., Hartmann, J.-M., Hill, C., Hodges, J. T., Jacquemart, D., Jolly, A., Lamouroux, J., Le Roy, R. J., Li, G., Long, D. A., Lyulin, O. M., Mackie, C. J., Massie, S. T., Mikhailenko, S., Müller, H. S. P., Naumenko, O. V., Nikitin, A. V., Orphal, J., Perevalov, V., Perrin, A., Polovtseva, E. R., Richard, C., Smith, M. A. H., Starikova, E., Sung, K., Tashkun, S., Tennyson, J., Toon, G. C., Tyuterev, Vl. G., and Wagner, G.: The HITRAN2012 molecular spectroscopic database, J. Quant. Spectrosc. Ra., 130, 4-50, 2013.

Saikawa, E., Rigby, M., Prinn, R. G., Montzka, S. A., Miller, B. R., Kuijpers, L. J. M., Fraser, P. J. B., Vollmer, M. K., Saito, T., Yokouchi, Y., Harth, C. M., Mühle, J., Weiss, R. F., Salameh, P. K., Kim, J., Li, S., Park, S., Kim, K.-R., Young, D., O'Doherty, S., Simmonds, P. G., McCulloch, A., Krummel, P. B., Steele, L. P., Lunder, C., Hermansen, O., Maione, M., Arduini, J., Yao, B., Zhou, L. X., Wang, H. J., Elkins, J. W., and Hall, B.: Global and regional emission estimates for HCFC-22, Atmos. Chem. Phys., 12, 10033-10050, doi:10.5194/acp-12-10033-2012, 2012.
Sharpe, S. W., Johnson, T. J., Sams, R. L., Chu, P. M., Rhoderick, G. C., and Johnson, P. A.: Gas-phase databases for quantitative infrared spectroscopy, Appl. Spectrosc., 58, 1452-1461, 2004.

Snels, M. and D'Amico, G.: Diode Laser Jet Spectra and Analysis of the $v_{3}$ and $v_{8}$ Fundamentals of $\mathrm{CHF}_{2} \mathrm{Cl}$, J. Mol. Spectrosc., 209, 1-10, 2001.

Solomon, S.: Stratospheric ozone depletion: A review of concepts and history, Rev. Geophys., 37, 275-316, 1999.

Thompson, C. D., Robertson, E. G., and McNaughton, D.: Highresolution FTIR spectroscopy of chlorodifluoromethane: $v_{2}$ and $v_{7}$, Chem. Phys., 279, 239-248, 2002.

Varanasi, P. and Chudamani, S.: Infrared intensities of some chlorofluorocarbons capable of perturbing the global climate, J. Geophys. Res., 93, 1666-1668, 1988.

Varanasi, P., Li, Z., Nemtchinov, V. and Cherukuri, A.: Spectral absorption-coefficient data on $\mathrm{HCFC}-22$ and $\mathrm{SF}_{6}$ for remotesensing applications, J. Quant. Spectrosc. Ra., 52, 323-332, 1994.

Velazco, V. A., Toon, G. C., Blavier, J.-F. L., Kleinböhl, A., Manney, G. L., Daffer, W. H., Bernath, P. F., Walker, K. A., and Boone, C.: Validation of the Atmospheric Chemistry Experiment by noncoincident MkIV balloon profiles, J. Geophys. Res., 116, D06306, doi:10.1029/2010jd014928, 2011.

Watanabe, K.: Optimum selection of refrigerants under environmental constraints, in: Low Temperature and Cryogenic Refrigeration, edited by: Kakaç, S., Avelino, M. R., and Smirnov, H. F., Springer Science + Business Media, Dordrecht, the Netherlands, 83-100, 2003. 